\title{
Inhaltsverzeichnis
}

Einleitung

\section{WISSENSCHAFTLICHE GESCHICHTE}

JOHANNES ROHBECK

Die narrative Funktion der Geschichtsteleologie

WILHELM SCHMIDT-BIGGEMANN

Die Gewalt der Erwartungen. Einige theoretische Bemerkungen

zur Geschichtsschreibung am Beispiel Condorcets

PETER-ANDRÉ ALT

Natur, Zivilisation und Narratio. Zur triadischen Strukturierung

von Schillers Geschichtskonzept

\section{ENZYKLOPÄDIK}

SEBASTIAN NEUMEISTER

Pierre Bayle oder die Versuchung der Geschichten 73

Claudia Albert

Verschwendung, Verknappung, Leerstelle.

Diderots, Wissenschaftspoetik ${ }^{6}$ 85

\section{PETER BROCKMEIER}

Innovation und Destruktion in der Genieästhetik 95

\section{LITERATUR}

\section{VEIT ELM}

Wissenschaftliche Geschichte und Literatur bei Fontenelle,

Montesquieu, Voltaire und Rousseau

HELMUT PFEIFFER

Erzählte und entzogene Individualität. Rousseau zwischen

Confessions und Rêveries 


\section{TORSTEN KÖNIG}

„Étudier la nature comme font les grands peintres“. Erzählung und Tableau in Bernardin de Saint-Pierres Naturbeschreibung

\section{YANN LAFON}

Die dialogische Transzendierung materialistischer Erkenntnistheorie

in Diderots Rêve de d'Alembert

Autorenverzeichnis

Namen- und Sachverzeichnis 